\title{
Anglo-americanismo e industrialismo nos primórdios da república brasileira: Roberto Cocrhane Simonsen (1889- 1948) e o trabalho moderno
}

\author{
Anglo-americanism and industrialism in the beginning of the \\ brazilian republic: Roberto Cocrhane Simonsen (1889-1948) and \\ modern labor
}

\author{
José Geraldo Pedrosa \\ Orcid: https://orcid.org/0000-0002-8295-8313 \\ Centro Federal de Educação Tecnólogica de \\ Minas Gerais, Divinópolis, Brasil, \\ jgpedrosa@uol.com.br
}

DOI: 10.21680/2596-0113.2021v4nOID26851

Citation: Pedrosa, J. G. (2021). Anglo-

americanismo e industrialismo nos primórdios da república brasileira: Roberto Cocrhane Simonsen (1889-1948) e o trabalho moderno. History of

Education in Latin America - HistELA, 4, e26851.

Competing interests: The author have declared that no competing interests exist.

Editor: Olivia Morais de Medeiros Neta

Received: 06/10/2021

Approved: 29/10/2021

OPEN ACCES

\section{Resumo}

O artigo é sobre a presença do anglo-americanismo na cultura empresarial brasileira e o foco é no engenheiro, intelectual e industrialista Roberto Cocrhane Simonsen, atuante na primeira metade do século XX. O objetivo da abordagem é destacar o repertório de argumentos de Simonsen como intelectual orgânico do industrialismo em seu empenho visando difundir a administração científica da produção e do trabalho e em fazer o Brasil seguir as trilhas anglo-americanas. A referência empírica está em pronunciamentos ou relatórios feitos por Simonsen e publicados em 1919. Os resultados indicam que Simonsen era americanófilo e foi importante na (re)formação do novo homem para o industrialismo urbano e de massas no Brasil.

Palavras-chave: Roberto Simonsen. Angloamericanismo. Industrialismo. Trabalho. Ensino Industrial.

\begin{abstract}
The article is about the presence of Anglo-Americanism in the Brazilian business culture and the focus is on the engineer, intellectual and industrialist Roberto Cocrhane Simonsen, active in the first half of the 20th century. The aim of the approach is to highlight Simonsen's repertoire of arguments as an organic intellectual of industrialism in his effort to spread the scientific management of production and work and to make Brazil follow AngloAmerican paths. The empirical reference is in statements or reports made by Simonsen and published in 1919. The results indicate that Simonsen was an Americanophile and was important in the (re)formation of the new man for urban and mass industrialism in Brazil.
\end{abstract}

Keywords: Roberto Simonsen. Anglo-Americanism. Industrialism. Work. Industrial Education. 


\section{Introdução}

Este artigo situa-se no âmbito de um programa de estudos e pesquisas cujos cujo foco envolve anglo-americanismo, trabalho e educação. De modo especial focaliza, a circulação de ideias, técnicas e práticas de origem anglo-americana na educação profissional brasileira. Os significados e as conexões entre angloamericanidade, anglo-americanismo e anglo-americanização serão definidos ao longo do artigo como contraparte de europeísmo. O conceito busca captar esse movimento pelo qual a anglo-americanidade se credencia como modelo civilizatório. Anglo-americanidade e anglo-americanismo são termos pertencentes à mesma base conceitual, mas seus significados têm singularidades. Todos esses termos são referentes aos Estados Unidos da América (EUA) e sua relação com os demais países, economias e culturas. São também contrapontos para modernidade e modernismo. A modernidade é europeia e identificada com o Renascimento e com o lluminismo. Modernismo é expressão que se refere à expansão da modernidade ou à chegada da modernidade europeia em outros territórios. Sentidos análogos são os de anglo-americanidade e anglo-americanismo. O primeiro binômio indica que a civilização anglo-americana é acontecimento consistente, estrutural, de longa duração e inédito em relação à modernidade europeia e seus referentes renascentistas e iluministas. Já o segundo binômio, anglo-americanização, equivale à expansão da anglo-americanidade, à circulação de ideias ou de traços culturais da civilização anglo-americana em territórios outros. Anglo-americanismo é mais uma atitude adesista à anglo-americanidade.

O que aqui se denomina de ensino industrial é isso que toma corpo e formato de redes nacionais no Brasil desde de 1942. Uma dessas redes surge voltada para a formação de mãos de obra: o Serviço Nacional de Aprendizagem Industrial (Senai). Outra rede nasce voltada para a formação de cabeças de obra ${ }^{1}$ ou de técnicos para a indústria, são as escolas técnicas, que surgem locais para se tornarem, nos anos 1940, rede federal. Agentes do ensino industrial é expressão que faz referências a um conjunto de engenheiros, engenheiros-educadores e educadores que nos anos 1930 e 1940 exerceram influência sobre o Governo Vargas, principalmente por meio do Ministério da Educação e da Saúde, e participaram da constituição e instituição das redes nacionais de ensino industrial. Esses agentes poderiam ser chamados de intelectuais do ensino industrial, mas, a rigor, nem todos tinham o status de intelectual. A abrangência do conceito de intelectual e da categoria intelectuais tem aqui o sentido posto por Sirinelli (1996): engajado em movimentos e manifestos, identificado com uma geração, seus temas e seus problemas, reconhecido em círculos e lugares de sociabilidade.

Ambas as redes de ensino industrial - o Senai e as escolas técnicas respondiam às demandas do boom de industrialização vivido pelo Brasil desde a Segunda Guerra Mundial. Mas a substituição de um modelo agroexportador por uma perspectiva que tomasse a indústria como carro-chefe da vida econômica e social foi o resultado de cumulativa afirmação dos assim chamados industrialistas. Os industrialistas circularam em São Paulo, no Rio de Janeiro, no Rio Grande do Sul e em Minas Gerais, no final do século XIX e início do século XX, nos ambientes das escola politécnica de São Paulo e do Rio de Janeiro, da Escola de Engenharia de Porto Alegre e da Escola de Minas de Ouro Preto-MG. Gradativamente os industrialistas se tornaram um movimento mais abrangente, passando a mobilizar e a expressar-se nos meios políticos e empresariais. Em 1941, quando o Brasil 
acelerava seu processo de industrialização, Getúlio Vargas, por meio do ministro da Educação e Saúde, Gustavo Capanema, convocou os industrialistas Euvaldo Lodi, presidente da Confederação Nacional da Indústria (CNI), e Roberto Cochrane Simonsen, presidente da Federação das Indústrias de São Paulo (Fiesp), para realizar estudos, na companhia de Valentim Rebouças, visando à estruturação das redes de ensino industrial para formar técnicos e trabalhadores em larga escala e com agilidade, de modo a equacionar uma das exigências da aceleração industrial. A iniciativa do Governo Vargas de convocar os dois industrialistas era resultado de um processo que já estava posto desde a Constituição Federal de 1937, da qual Roberto Simonsen era signatário. Antes, a Divisão do Ensino Industrial, do Ministério da Educação e da Saúde, sob o comando do diretor, Francisco Montojos², já havia elaborado um anteprojeto que previa a criação de escolas de aprendizes industriais, cujo intuito era cumprir o artigo 129 da Constituição de 1937. Além disso, à medida que expandia a industrialização brasileira, Capanema empreendia esforços rumo à promoção de reformas educacionais que abrangiam diferentes níveis e ramos do ensino. Para elaboração das reformas foram criadas comissões especiais de trabalho, entre elas a que tinha finalidade de pensar o ensino industrial no Brasil. Essa comissão foi composta por influentes engenheiros e educadores, entre os quais Roberto Simonsen, Euvaldo Lodi, Francisco Montojos, Lourenço Filho, Horácio da Silveira, Leon Renault, Rodolfo Fuchs e Roberto Mange.

$\mathrm{O}$ argumento de fundo do artigo é que a afirmação do industrialismo e a institucionalização do ensino industrial em rede no Brasil a partir dos anos 1940 revelam uma crescente presença de referências anglo-americanas. Nesse período, enquanto a Europa se fechava com o totalitarismo nazifascista, os EUA afirmavamse como referência de democracia liberal, de economia industrial e de incorporação das massas à produção e ao consumo. Os agentes do industrialismo tinham em seu imaginário a formação de um Brasil industrial, urbano e de massas e com uma cultura empresarial orientada pela administração científica da produção e do trabalho, típica do modelo anglo-americano.

O foco do artigo é sobre um eminente intelectual orgânico do empresariado brasileiro com intensa atuação na primeira metade do século XX. Roberto Simonsen era engenheiro de formação, industrialista por convicção e anglo-americanista por admiração. Descendente de ingleses, era um típico anglo-americanófilo, assim como seus contemporâneos Anísio Teixeira, Lourenço Filho e Monteiro Lobato. Roberto Simonsen era empresário bem-sucedido, foi deputado e senador no Estado Novo, professor, intelectual e líder empresarial destacado. Stricto sensu, foi intelectual e intelectual orgânico. Sua expressão como intelectual está na autoria de cerca de trinta livros. Como intelectual orgânico foi fundador e atuante na Federação das Indústrias do Estado de São Paulo (Fiesp), na Confederação Nacional da Indústria (CNI) e no Instituto de Organização Racional do Trabalho (Idort). Roberto Simonsen foi homem de teoria, de articulação e de ação. Foi um símbolo do pensamento industrial brasileiro, um republicano e adversário dos coronéis do latifúndio e sua herança escravista. Roberto Simonsen foi um dos agentes do ensino industrial no Brasil; foi figura importante na (re)formação de trabalhadores e empresários para a indústria brasileira, ou seja, na preparação do novo homem para o industrialismo urbano e de massas.

A abordagem feita no artigo destaca o empenho de Roberto Simonsen em difundir no Brasil os princípios e as práticas de administração científica da produção e do trabalho. O artigo também visa a demonstrar a inspiração anglo-americanista de Roberto Simonsen e seu esforço em fazer o Brasil seguir as trilhas dos EUA. A referência empírica da abordagem é um conjunto de pronunciamentos ou de 
preâmbulos de relatórios empresariais feitos por Roberto Simonsen e publicados no ano de 1919. O artigo começa pela elaboração do significado de angloamericanismo e sua relação com o europeísmo. A meta é demonstrar a singularidade da anglo-americanidade e o seu caráter inédito na cultura ocidental. Em seguida, a abordagem focaliza a difusão do anglo-americanismo na cultura empresarial brasileira em expressões de Roberto Simonsen.

\section{Ocidente e $o$ anglo-americanismo}

O Ocidente não é igual ao Oriente. Essa diferença que delineia a formação cultural da Europa tem sua origem numa bifurcação civilizatória bastante antiga. Há quem diga que ela é do século XVI: em sua gênese estaria a dessacralização da vida e a antropocentricização do mundo. Touraine (1997) afirma que, no século XVI, a modernidade ainda era embrionária para só tornar-se triunfante nos séculos XVIII e XIX com as revoluções burguesas e industrial. O século XVI é o contexto do mercantilismo e da formação do homo econômico: Marx (1982) captou esse processo em sua análise sobre a acumulação primitiva na Inglaterra. É também o contexto do absolutismo e da dessacralização da política. O príncipe, de Maquiavel (MCMLXXVI) ou o Leviatã, de Hobbes (1983), são expressões desse processo de humanização da política. É a época da reforma protestante, da remoção de obstáculos espirituais e da inversão do valor do trabalho, que passa a ter um fim em si, ou seja, passa a ser revelação de vocações. Por força das metamorfoses políticas, econômicas e culturais, o século XVI é a época do Renascimento. Durkheim (1995) e Weber (1993) são exemplares no entendimento desse movimento: o primeiro, com a noção de sociedades complexas ou da associação entre complexização do corpo social e o fenômeno da individuação; o segundo, com a ideia de modernidade ou da relação entre progresso da ciência e o desencantamento da vida.

Mas há quem atribua raízes bem mais remotas à formação cultural da Europa, a essa diferenciação do caráter ocidental ou a esse processo de formação de uma nova estrutura de caráter. O próprio Weber cogita a possibilidade de remetêla ao século IV a.C. Aqui a cultura europeia ou o Ocidente são identificados com a racionalidade e, portanto, com a Filosofia. Adorno e Horkheimer (1985) identificam raízes mais remotas ainda. Para eles, Ulisses, o herói homérico, é o protótipo do indivíduo burguês. Para os frankfurtianos, o espírito burguês é identificado com a aventura e com o risco, mas, também, com a calculabilidade e com a frieza, com a dominação, com a astúcia e com a violência. Tudo isso já estava presente na Odisseia, a primeira doutrina voltada para a formação do caráter ocidental.

Lefebvre é mais remoto ainda em sua hipótese sobre a formação cultural do Ocidente ou da Europa: século XII a.C. Para ele a origem do Ocidente estaria numa vida mais movimentada que na Ásia. Nesse contexto, tanto o Oriente quanto o Ocidente eram comunidades agrárias. Todavia, no Ocidente essa base tribal foi transformada pelo nomadismo. Isso teve consequências e deu outro sentido à vida comunal. O principal trabalho comum era a guerra: "(...) a comunidade se organiza primeiro militarmente e não administrativamente, como no Oriente" (Lefebvre, 2001, p. 93). Daí decorre outra diferença: a base dessa organização militar é a cidade. A vida social ocidental não teve por base o campo, "(...) mas a cidade erigida em sede (centro) para as pessoas do campo, os proprietários agrários" (Lefebvre, 2001, p. 
92). Assim, a condição inicial da civilização ocidental foi o nomadismo tardio, a instabilidade, a migração e a agressividade.

Essas diversas considerações permitem pensar que não é a ausência ou presença de tradição que diferenciam Ocidente. A particularidade do Ocidente não é a falta de tradição, mas, a presença de uma tradição peculiar. A produção e a troca existem em diversos lugares, mas só no Ocidente são racionalizadas e se submetem à lógica do lucro permanente. Assim, há uma dissociação entre a produção e a necessidade, entre mercado e sociedade. Isso é próprio do ocidentalismo europeu: nisso estão de acordo Weber e Marx. Ocorre, no entanto, que esse ocidentalismo eurocêntrico se esgotou lentamente, ou melhor, a tradição europeia impôs gradativos limites à reprodução ampliada do capital. A Europa inventou o capitalismo, mas sua tradição milenar acabou tornando-se um obstáculo à ampliação constante do mercado, e, com ele, à ética do trabalho e aos prazeres do consumo. Limites endógenos, mais provenientes da cultura e da política, levaram o capitalismo a um processo de estagnação, isto é, ausência de crescimento. Isso é suficiente para inviabilizar a livre concorrência: a relação entre a oferta e a demanda é semelhante à do fogo com o oxigênio.

O mais contundente sintoma desse esgotamento do europeísmo foi a experiência totalitária e a Segunda Guerra, ao final da primeira metade do século XX. A Europa desmoronou-se em sua potência militar, econômica e política. Com isso, o Ocidente foi alvo de uma virada civilizatória: simultaneamente ao declínio do velho mundo se firmou além-mar um novo mundo, a anglo-americanidade.

Mas, afinal, o que a relação entre modernidade e anglo-americanidade permite pensar? Uma primeira questão seria relativa à continuidade ou ruptura entre o velho e o novo mundo: seriam os EUA a realização dos ideais europeus ou a anglo-americanidade constitui um fato cultural inédito, um novo estilo de vida, um novo modo de dominação e um novo homem? A perspectiva aqui adotada é de que a anglo-americanidade é inédita e constitui uma virada civilizatória, um acontecimento radical com desdobramentos múltiplos: na economia, na política, na sociedade, na cultura, na epistemologia e na relação com a natureza. No sentido original, o anglo-americanismo é a renovação da capacidade reprodutiva do sistema produtor de mercadorias. Nesse sentido anglo-americanismo é fordismo. Mas o fordismo é muito mais que um modus operandi da fábrica, é um modus vivendi, a plena integração entre homem e máquina.

Essa associação entre anglo-americanismo e fordismo é de Gramsci (2001). O industrialismo é europeu, mas em território anglo-americano ele se associa à massificação do consumo e isso tem consequências: a sociedade torna-se uma imensa engrenagem de produção e de consumo visando ao lucro. Gramsci usa a metáfora da moenda para relacionar europeísmo e anglo-americanismo. Para ele, o anglo-americanismo não é original, mas é inédito, ou seja, o anglo-americanismo configura-se como a filosofia que se afirma na ação, no pragmatismo. A diferença entre o velho e o novo mundo é definida pela ausência de tradição e dos privilégios sociais herdados: a capa de chumbo ou o peso do passado hierarquizante. $\mathrm{Na}$ ausência desse passado pesado, os valores europeus efetivam-se, na América, num modo singular de pensar, de sentir, de viver e de relacionar-se. É por isso que o anglo-americanismo constitui um novo mundo, que requer um novo homem, com uma nova conformação psicofísica. O americanismo-fordismo é a regulação planejada da sociedade nas esferas pública e privada. É nesse sentido que o homem se integra à máquina: ambos são peças de uma força produtiva, o fordismo. Os homens e as máquinas formam um todo orgânico. Nesse sentido, o fordismo não é somente um modus operandi da produção, algo circunscrito ao chão das 
fábricas. É um estilo de vida, uma nítida expressão da modernidade apropriada pelo capital. É um fenômeno que requer mudanças profundas em relação à cultura europeia. É isso que demarca a diferença entre modernidade e angloamericanidade.

Nesse ponto, a distinção entre anglo-americanidade e anglo-americanismo pode também ser retomada. Uma vez constituída e bem-sucedida, a angloamericanidade torna-se referência, modelo, fonte de inspiração; torna-se angloamericanismo para concorrer com o europeísmo. Weber (1993, p. 20) captou até mesmo a Alemanha imitando os EUA, ainda no limiar do século XX, quando a Europa ainda era triunfante. "Tal como se dá em outros setores da nossa vida, a universidade alemã se americaniza, sob importantes aspectos”. Weber (1993, p. 20) não só captou a presença do anglo-americanismo na universidade alemã, como identificou essa imitação como sinal de progresso: "Não se podem negar as incontestáveis vantagens técnicas dessa evolução, (...) o 'novo espírito' é bem diferente da velha atmosfera histórica das universidades alemãs".

No Brasil, segundo Warde (2000, p. 16), aos poucos, “(...) os Estados Unidos vão se afigurando nos ensaios utópicos das elites intelectuais e no imaginário social como a terra prometida, sem as mazelas da Europa envelhecida e conflituosa". No Brasil, a presença anglo-americana na política e na educação vem desde o final do século XIX e intensifica-se ao logo de todo o século XX com base em um movimento centrípeto e outro centrífugo. O movimento centrípeto expressa-se na capacidade anglo-americana de atrair a atenção de ocupantes de cargos públicos, de homens negócios ou de intelectuais brasileiros que para lá se dirigem com a finalidade de apropriar-se de experiências, técnicas e ideias ou buscar comparações ou inspirações para o enfrentamento, em terras tupiniquins, de problemas diversos, numa sociedade que aspirava à cultura republicana, mercantil e industrial.

Entre os primeiros brasileiros a buscarem inspiração na angloamericanidade, ainda no século XIX, estavam Rui Barbosa, Maria Guilhermina Loureiro ${ }^{3}$ e Antônio Augusto de Oliveira ${ }^{4}$. Barbosa foi em busca de modelo para a lei das leis, ou seja, para a Constituição republicana de 1889; Loureiro e Oliveira foram em busca de modelos pedagógicos. Na primeira metade do século XX entre os viajantes mais ilustres estavam Anísio Spíndola Teixeira, José Bento Monteiro Lobato, Manuel Bergström Lourenço Filho, Roberto Cochrane Simonsen, Américo Giannetti e Clodomir Viana Moog. Teixeira foi conhecer John Dewey e sua filosofia da educação; Lobato foi como adido comercial; Lourenço Filho foi conhecer escolas e a psicologia da educação; Simonsen foi ver de perto a administração científica da produção e do trabalho, ou seja, o taylorismo; Giannetti foi aprender a fabricar alumínio; e $\mathrm{Moog}^{5}$ foi para pesquisa social stricto sensu. Todos eles difundiram a anglo-americanidade e fizeram circular no Brasil ideias de origem anglo-americana.

A presença da anglo-americanidade no Brasil por meio do movimento centrífugo também ocorre desde o século XIX, mas de modo mais intenso e extenso foi a partir dos anos 1930. Após a guerra civil anglo-americana de 1865, fazendeiros do sul dos EUA, inconformados com a derrota e com o fim da escravidão, migraram para São Paulo e trouxeram dinheiro, cultura e técnicas agrícolas, entre as quais o arado. A cidade chamada Anglo-americana, em São Paulo, é uma expressão da presença de migrantes dos EUA em terras brasileiras. Mas foi nos anos 1930 e 1940, com o rádio, o cinema e, depois, com a televisão, que a indústria cultural anglo-americana espalhou novos comportamentos entre as populações urbanas brasileiras. 
Fato é que em meio a esses movimentos culturais centrípetos e centrífugos, ao final do século XIX e longo do século XX, Brasil e EUA intensificaram suas relações políticas, econômicas e educacionais por meio de uma série de acordos bilaterais. Acordos emblemáticos que resultaram em presença mais intensa dos modelos anglo-americanos no Brasil foram os dos anos 1940, no contexto da Segunda Guerra. A declaração de apoio do Governo Vargas aos países aliados em 1942, o envio de pracinhas aos campos de batalha na Europa e a cessão do litoral brasileiro para a logística de guerra geraram dívidas e dividendos ao Brasil. $\mathrm{Na}$ economia, a industrialização brasileira foi acelerada em decorrência do aumento das exportações e da entrada de capitais, indústrias, técnicas e técnicos de origem anglo-americana. É dessa época a Companhia Siderúrgica Nacional (CSN), responsável pelo ciclo siderúrgico; a Fábrica Nacional de Motores (FNM); a Companhia Vale do Rio Doce (CVRD) e a Aços Especiais Itabira (Acesita), na zona metalúrgica de Minas Gerais. É nessa época também que a Coca Cola começou a instalar suas fábricas no Brasil, pelo sistema de franquias.

Um marco emblemático da presença da anglo-americanidade na educação brasileira foi o acordo bilateral que resultou na criação da Comissão BrasileiroAnglo-americana de Ensino Industrial (CBAl). Nos anos 1940, a aceleração industrial exigia a formação, em grande escala e com agilidade, de um novo tipo de trabalhador e de consumidor; formação de um novo homem, urbano e apto à administração científica do trabalho e da produção. Foi para atender a essa demanda que o Brasil instituiu duas redes de ensino industrial, sendo uma para formação de mão de obra e outra para formação de cabeça de obra, ou seja, para a formação de trabalhadores e de técnicos. Para a preparação de trabalhadores industriais foi instituído o Senai e para a formação de técnicos industriais foi instituída a rede federal de escolas técnicas, no lugar dos Centros de Artes e Ofícios que haviam sido criados em 1911. A instituição dessas duas redes e a necessidade de formação de trabalhadores em grande escala levaram o Brasil a deparar-se com a demanda de formação de professores para o ensino industrial, ou seja, dos professores de cultura técnica ou dos professores de oficina. Para essa função, além do domínio prático do ofício a ser ensinado - do saber-fazer - era necessário saber ensinar e saber como o outro aprende. Ou seja, eram necessárias a metodologia ou a didática e a psicologia do ensino industrial. O problema é que o Brasil não dispunha de professores com esse perfil e era preciso formá-los com agilidade. Mas o Brasil também não dispunha da expertise necessária à formação desses professores. Foi necessário buscar amparo em experiências internacionais e não seria na Europa totalitária que o Brasil se apoiaria. É dos EUA que veio tal suporte. Para isso, a CBAl criou a Biblioteca do Ensino Industrial, com livros de didática e psicologia, entre outros, todos de origem norte-anglo-americana. Além disso, foram realizadas várias viagens para intercâmbio entre professores do Brasil e dos EUA.

É nesse processo de aproximação política, econômica, cultural, iniciado no século XIX, amadurecido após a República e intensificado na era Vargas, que nossas elites mudaram o seu olhar e o seu campo de referências, preferências e aliados internacionais. 


\section{Roberto Roberto Simonsen e a circulação do anglo- americanismo no Brasil}

Não constituía exceção, já na primeira metade do século $X X$, que homens de vanguarda do industrialismo brasileiro declarassem admiração pelos modelos que vinham do norte, que realizassem viagens aos EUA para aquisição de know-how e que fizessem circular no Brasil ideias e práticas industriais típicas do angloamericanismo. Afinal, como enfatizava Gramsci (2001), é de lá que vinha esse novo vigor do capitalismo, incrementado com novas formas de hegemonia que contemplavam a administração científica, a elevação da produtividade a níveis inéditos, a massificação do consumo e novas práticas de regulação. Era o sucesso anglo-americano que inspirava muitos industrialistas brasileiros de vanguarda nas inovações organizacionais e gerenciais que adotavam em suas indústrias e nas pressões e negociações com o Estado Novo, visando à elaboração e implementação de políticas públicas que impulsionassem o capitalismo industrial. Nesse processo, um foco particular de circulação de ideias anglo-americanas era o ensino industrial que, nos anos 1940, estava sendo incrementado no Brasil, tanto por meio do Senai, na formação de operários, quanto na rede federal de escolas técnicas, na formação de técnicos para a indústria em expansão.

Nesse cenário inicial do século $X X$ e de república embrionária, um dos intelectuais orgânicos dos industrialistas brasileiros era Roberto Cochrane Simonsen, um declarado adepto do anglo-americanismo e responsável por circular no Brasil ideias relativas à administração científica da produção e do trabalho. Roberto Simonsen era um bem-sucedido empresário paulista ligado à construção civil, à indústria frigorífica e a outros ramos industriais. Era um inovador da gestão industrial, um homem de referência para o industrialismo nascente. Sua atuação ultrapassava o âmbito interno das empresas que dirigia e adentrava a cena política num Brasil fortemente latifundiário, coronelista e marcado pela herança escravocrata.

Roberto Simonsen nasceu um ano após a abolição da escravatura e no mesmo ano do movimento civil-militar que deu origem à República brasileira, ou seja, 1889. A República brasileira e Roberto Simonsen são gêmeos. Roberto Simonsen era descendente de família nobre, era homem de posses. Faleceu em 1948, no Rio de Janeiro, em pleno salão nobre da Academia Brasileira de Letras, da qual era ocupante de uma cadeira. Roberto Simonsen era engenheiro formado no berço do industrialismo brasileiro - Escola Politécnica de São Paulo - e destacou-se como empresário, político, escritor e memorialista. Ocupou cargos públicos no município de Santos (SP), participou ativamente na elaboração da Constituição brasileira de 1937, na condição de deputado constituinte por São Paulo no período de 1933 a 1937, e, nos anos 1940, elegeu-se senador da República. Antes disso, foi diplomata no governo de Epitácio Pessoa (1919-1922) e, no início dos anos 1930, fez parte do Movimento Constitucionalista que resistiu ao golpe de Estado protagonizado por Getúlio Vargas. Como acadêmico, participou da criação e fez parte do conselho diretor da atual Escola de Sociologia e Política de São Paulo, pioneira no ensino de Sociologia e de Política no Brasil. Por força de seu ofício de empresário do ramo industrial, foi presidente da Federação das Indústrias do Estado de São Paulo (Fiesp) e da Confederação Nacional da Indústria (CNI).

Roberto Simonsen foi homem de ideias e de ação, gestor de empresas e de instituições sindicais patronais, além de articulador político. Era homem articulado, um intelectual e professor com boa capacidade de oratória. No legado de Roberto 
Simonsen figuram muitos livros sobre a história e a economia brasileiras. Há também muitos de seus pronunciamentos que ficaram documentados. Roberto Simonsen foi homem de referência e de influências. Para as elites brasileiras foi um homem exemplar. Um típico membro da intelligentia nacional: "homem culto, orador, eloquente, nacionalista e defensor apaixonado de mudanças sociais"6. (VIEIRA, 2008, p. 68). Pioneiro em vários aspectos da cultura empresarial brasileira, Roberto Simonsen é aqui destacado como um dos primeiros brasileiros a entenderem o significado da ascensão dos EUA no plano econômico mundial. Ou seja, é um dos pioneiros na circulação de ideias anglo-americanas no Brasil.

Simonsen (1919, p. 34) preocupava-se em aplicar em suas empresas a reorganização interna "(...) em moldes mais chegados aos da administração scientifica, adoptados ultimamente pelas grandes indústrias anglo-americanas"7. Mas Roberto Simonsen tinha uma perspectiva nacional e buscava uma intervenção com vistas à formação de uma cultura empresarial compatível com a modernização industrial e das relações de trabalho. Em 1919, ano do fim da Primeira Grande Guerra, fez publicar O trabalho moderno, destinado aos empresários nacionais.

Este pequeno livro com pouco mais de quarenta páginas não contém nenhuma elaboração conceitual sofisticada. Pelo contrário, é um conjunto de pronunciamentos proferidos em cerimônias políticas ou de preâmbulos de relatórios que Roberto Simonsen escrevera às diretorias das empresas das quais era superintendente. A despeito da modéstia e da despretensão manifestada pelo próprio autor, que advertia para a imponência do título em relação ao conteúdo do texto, tratava-se de um folheto militante ou de um instrumento de intervenção na cultura empresarial e política brasileiras. Era, pois, um texto educativo na medida em que expressava uma intervenção para a mudança da mentalidade e das práticas empresariais. O que movia Simonsen (1919, Prefácio) a dar publicidade às suas práticas como empresário, segundo ele mesmo, eram as circunstâncias sociais: "(...) obrigavam-me a apparecer fora do campo industrial onde trabalho incessantemente em obediência ao culto que professo pela acção e ao programa que tracei para a minha vida". Roberto Simonsen era homem de negócios e de ideias e pertencia a uma consistente rede de sociabilidade. Uma de suas relações era com Monteiro Lobato, esse intelectual brasileiro amante das coisas dos EUA.

Roberto Simonsen transpirava anglo-americanismo em circunstâncias as mais diversas. Seu pequeno livro de 1919 é exemplar dessa capilaridade do angloamericanismo em suas intervenções. O livro é organizado em três partes. A primeira tem como título "Pelo trabalho organizado"; a segunda parte intitula-se "Pela organização da produção" e, a terceira, "Pela administração científica". A despeito da pompa dos títulos, mais compatíveis com um tratado de aplicação da ciência na gestão da produção e do trabalho, os textos são constituídos por dois pronunciamentos e pela introdução de um relatório empresarial. São três textos elaborados em circunstâncias específicas e destinados a públicos distintos. A circulação de ideias pertencentes ao anglo-americanismo nesses diferentes textos é indício do entusiasmo que Roberto Simonsen tinha pelas coisas anglo-americanas e também da percepção que ele tinha dos EUA como um acontecimento civilizatório inédito e como um modelo para o Brasil, notadamente para as culturas empresarial e política.

O primeiro texto do livro - "Pelo trabalho organizado" - é um agradecimento proferido em 1918 por ocasião do término do combate a uma epidemia de gripe na cidade de Santos, onde Roberto Simonsen, aos 29 anos, ocupava o cargo de diretor-geral de obras na Prefeitura. A cerimônia na qual foi proferido o pronunciamento tinha um público eclético, constituído por pessoas de seu 
relacionamento pessoal e por funcionários públicos e voluntários envolvidos no combate à epidemia. Segundo o próprio autor, a reunião era uma manifestação de reconhecimento à sua atuação no comando das bem-sucedidas ações de erradiação da epidemia.

Em seu pronunciamento, Roberto Simonsen faz referências positivas aos EUA e dá publicidade a ideias típicas do anglo-americanismo. Numa das passagens, Simonsen não cita os EUA, mas faz uma intervenção que traduz reconhecimento de uma diferença significativa entre o velho e o novo mundo: a luta de classes. O confronto entre capital e trabalho foi um dos traços marcantes na revolucionária Europa do século XIX. Lá, a exploração acentuada, as longas jornadas e as precárias condições de trabalho fizeram surgir a resistência sindical e os partidos comunistas com forte penetração no seio do proletariado. Roberto Simonsen via perspectiva diferente na cultura empresarial e nas relações de classe nos EUA. Aproveitando o momento de "cooperação voluntária e consciente" da qual "resultaram proveitos para todos nós", conseguido em face do "perigo de morte, a grande nivaladora social" e a consequente formação de uma "communidade de soffrimentos" que aproximou "patrões e empregados, auxiliares superiores e humildes operários", Roberto Simonsen apresenta uma lição de moral e civismo bem compatível com o espírito do novo capitalismo anglo-americano:

(...) agindo com esse pensamento, sempre unidos, contribuamos para evitar a todo transe que sejam trazidas para o nosso Brasil as lutas de classe, as organizações artificiaes, os entraves á verdadeira noção de liberdade, que foram, em grande parte, as causas dessa campanha sangrenta que custou milhões de vidas de nossos semelhantes! (Simonsen, 1919, p. 10).

Vale, mais uma vez, enfatizar que esse pronunciamento foi proferido em 1918, ano do fim da Primeira Grande Guerra e um ano após a sangrenta Revolução Russa, ambas em solo europeu.

Mas, nesse supostamente despretensioso pronunciamento proferido numa cerimônia municipal, entre amigos e servidores públicos, ao fim do combate a uma epidemia, as intevenções a favor de uma nova mentalidade empresarial inspiradas no anglo-americanismo são reincidentes. Roberto Simonsen não apenas menciona traços da cultura anglo-americana, mas, diversas vezes, cita os EUA como referência a ser seguida.

Noutra passagem, Simonsen $(1919$, p. 10) refere-se ao problema da organização industrial no Brasil e faz a defesa da "organização scientifica, como denominam os norte-americanos". Ao referir-se às virtudes da ciência aplicada à produção e ao trabalho, Roberto Simonsen reconhece um traço da cultura angloamericana que dez anos mais tarde também seriam conferidos por Monteiro Lobato (1950), em seu livro América. Simonsen (1919, p. 10) salienta a eficiência angloamericana: "(...) a maxima economia na producção pela realização da maxima efficiencia". Para a obtenção da máxima eficiência a receita vinha do taylorismo:

Na moderna organização do trabalho, a antiga disciplina, á militar - que só se impunha pelo rigorismo de feitores carrancudos - é sbstituida pela disciplina intelligente e consciente oriunda do conhecimento exacto que tem o operario da natureza do seu trabalho e da certeza do justo reconhecimento de seus esforços. (Simonsen, 1919, p. 10). 
Ao longo do pronunciamento, expressões como administração científica, eficiência e barateamento da produção são reincidentes. Mas a advertência à cultura empresarial brasileira segue a linha de inspiração anglo-americana: "Esse barateamento, porém, deverá ser conseguido não á custa de vossos salarios, mas sim pela obtenção da maxima efficiência do trabalho!" (Simonsen, 1919, p. 11). Mas como obter a eficiência do trabalho? O segredo, ou melhor, a receita está na "(...) perfeita organização em que, por disposições intelligentes adoptadas, as perdas de tempo e os esforços productivos sejam reduzidos ao mínimo" (Simonsen, 1919, p. 11). Roberto Simonsen não usa a mesma expressão, mas sua intervenção vai no mesmo sentido daquela captura que Max Weber já fizera do espírito angloamericano ao referir-se à famosa frase de Benjamin Franklin: "Time is money". Simonsen (1919, p. 11-12) ainda não faz referências ao consumismo, mas é crítico do uso predatório da força de trabalho e partilha da lógica da maior recompensa na forma de elevação salarial para a obtenção da adesão do trabalhador: "Nos Estados Unidos as empresas mais bem organizadas, isto é, as que conseguem produzir mais barato, são as que pagam os mais altos salários". Aqui Simonsen (1919, p. 12) revela uma conexão não só com o taylorismo, mas, com o fordismo, que se expandiria nos EUA após a depressão de 1929:

(...) cooperação cordial ente patrões e operários". A máxima eficiência a ser obtida do trabalho teria que ter contrapartidas do capital não só na forma dos altos salários, da cooperação cordial, da disciplina inteligente, mas, também, nas "(...) condições de conforto e bem estar dos que trabalham.

É interessante como essa percepção que Roberto Simonsen tinha do industrialismo anglo-americano também fora detectada por Gramsci, que identificava no "americanismo-fordismo" uma coerção de novo tipo, fundada num novo princípio. Uma coerção "(...) sabiamente combinada com a persuasão e o consenso, e isto pode ser obtido (...) por meio de uma maior retribuição, que determina um determinado (sic) padrão de vida, capaz de manter e reintegrar as forças desgastadas pelo novo tipo de esforço" (Gramsci, 2001, p. 273). Gramsci via no anglo-americanismo não apenas uma forma de regulação da individualidade. Ele associava a mecanização do trabalho ou os automatismos a duas novas situações. A primeira é que a mecanização e a repetição de gestos no trabalho deixam o cérebro desimpedido para outras ocupações: "(...) caminhamos automaticamente e, ao mesmo tempo, podemos pensar em tudo que quisermos" (Gramsci, 2001, p. 272). A segunda situação é referente à insatisfação com o trabalho monótono e sem espírito e a possibilidade de rebelião do gorila: "(...) o trabalho não lhe dá satisfações imediatas, e que ele compreenda que se quer reduzi-lo a gorila amestrado, pode levá-lo a um curso de pensamentos pouco conformistas" (Gramsci, 2001, p. 272). É preciso criar novas recompensas e foi essa a invenção de Henry Ford em sua fábrica de automóveis: além de reduzir os custos da produção era necessário elevar os salários. Mas elevação dos salários tem suas contradições no que se refere à regulação da vida individual do trabalhador: "(...) é preciso que o trabalhador gaste 'racionalmente' o máximo de dinheiro para conservar, renovar e, se possível, aumentar sua eficiência muscular-nervosa, e não para destruí-la ou danificá-la" (Gramsci, 2001, p. 267). Nesse ponto o Estado é requisitado na "luta contra o álcool, o mais perigoso agente de destruição das forças de trabalho" (Gramsci, 2001, p. 267). É assim que Gramsci via o anglo-americanismo: “(...) combinação entre coação (autodisciplina) e persuasão" (Gramsci, 2001, p. 275). Isso ocorre ao evidenciar-se a possibilidade, pelo trabalho, de acesso a um novo padrão de vida, 
ou melhor, “(...) da possibilidade de realizar o padrão de vida adequado aos novos modos de produção e de trabalho, que exigem um particular dispêndio de energias musculares e nervosas" (Gramsci, 2001, p. 275).

Quando dois homens tão diferentes em seus pensamentos, intenções e ações convergem na interpretação desse traço do industrialismo anglo-americano, a constatação ganha força. É nesse sentido que Roberto Simonsen buscava nos EUA referências para a superação das heranças escravistas na cultura empresarial brasileira do início do século XX.

No segundo texto constitutivo do Trabalho moderno as referências ao angloamericanismo continuam a aparecer e cada vez com mais destaque. Esse segundo texto é também a transcrição de um pronunciamento com a diferença que, desta vez, proferido em uma cerimônia para um público bem diferentes do anterior. A cerimônia da vez foi um banquete oferecido nos últimos dias de 1918 em homenagem ao ministro da Agricultura, Antônio Pádua Sales. A cerimônia foi realizada em Santos (SP), cidade na qual o ex-secretário paulista da Agricultura e então ministro da Agricultura, Antônio Pádua Sales, fora empresário do comércio por vários anos antes de se dedicar à vida pública. Em 1918 Roberto Simonsen era jovem, não tinha destaque nacional, não havia sido presidente da Fiesp e da CNI nem deputado constituinte ou senador da República. É difícil de imaginar, pois, que ele tivesse alguma influência política sobre o governo federal a ponto de ter interferido na indicação de Pádua Sales para o Ministério da Agricultura. No período em questão a presidência da República era ocupada por Delfim Moreira, que assumiu em 1918 em decorrência do falecimento de Rodrigues Alves. Delfim Moreira era político mineiro e permaneceu na Presidência apenas até 1919, quando foi realizada nova eleição, cujo resultado levou ao poder Epitácio Pessoa. Se a indicação de Pádua Sales para o Ministério da Agricultura tivesse ocorrido no governo de Epitácio Pessoa, seria até razoável supor que o jovem Roberto Simonsen tivesse exercido alguma influência já que, neste governo, ele exerceu funções de diplomata.

Essas considerações são relevantes em virtude da natureza do pronunciamento proununciado por Roberto Simonsen no banquete oferecido ao ministro Pádua Sales. Se Roberto Simonsen não exerceu influência na indicação do ministro da Agricultura, o mesmo não pode ser dito em relação às políticas de governo praticadas pelo ministro. O pronunciamento é uma clara tentativa de influência na conduta de Pádua Sales no comando da agricultura. E, mais uma vez, toda a inspiração e toda a linha de raciocínio expressa nas palavras de Roberto Simonsen vêm do anglo-americanismo. O tempo todo Roberto Simonsen toma como referência as práticas e as experiências dos EUA com a agricultura e, com a mesma ênfase, recomenda que o Brasil as tome como referência.

Uma primeira referência vem do reconhecimento da importância do setor primário na constituição do produto interno bruto, mesmo nas economias altamente industrializadas. Simonsen (1919, p. 22) recorre aos EUA para legitimar sua ênfase:

Em principio deste seculo, mostrava uma estatistica que a expostação de productos agricolas da America do Norte apresentava um saldo líquido de mais de 6 billioes de dollars. Em dez annos a agricultura creou uma riqueza igual a metade de toda a fortuna publica anglo-americana acumulada em 3 seculos! 
Outra referência vinha da articulação entre os setores primário e secundário da economia. Na primeira metade do século $X X$, o Brasil tinha uma economia predominantemente agroexportadora, combinada com a hegemonia política dos grandes proprietários rurais. Os industrialistas, esse grupo articulado a partir do Sudeste brasileiro, travava uma disputa política com os coronéis da agroexportação e pleiteavam a industrialização como via de desenvolvimento do País. Entretanto, o pleito dos industrialistas não era pelo abandono da agropecuária e a favor da primazia da indústria, mas, sim, da adoção da lógica industrial para o conjunto da economia, inclusive para o setor primário. E isso tinha inspiração anglo-americana e era enfatizado nas palavras que Simonsen (1919, p. 22) dirigia ao ministro da Agricutura:

Referi-me atraz ao valor da producção industrial anglo-americana; pois no desenvolvimento economico dos Estados Unidos a agricultura manteve e mantém papel preponderante! Foi nella que a America buscou os elementos de vida para as suas industrias, ás quaes a lavoura não fornecia apenas a materia prima, proporcionava tambem ás usinas os seus capitaes.

E quais eram as referências para uma associação ente os setores primário e secundário da economia ou qual era o significado dessa industrialização da agropecuária? Roberto Simonsen não teorizava nem demonstrava sua convicção em fórmulas abstratas. Na condição de adepto do pragmatismo, ele recorria a resultados e a exemplos. A questão fundamental que Roberto Simonsen queria demonstrar ao ministro Pádua Sales era sobre como incrementar a agropecuária brasileira, de modo a elevar sua produtividade. Simonsen (1919, p. 22-23) insistia em mostrar a Pádua Sales as virtudes da agricultura anglo-americana:

\begin{abstract}
Esse augmento de riqueza, esse desenvolvimento da agricultura anglo-americana, que começou a ser observado principalmente nos ultimos 50 annos é fructo legitimo do trabalho associado, do cerebro, do musculo e da machina; é fructo de uma cultura intelligente, intensiva, de melhores methodos e de um emprego judicioso do solo; é devido á execução de trabalhos uteis, á drenagem, á irradiação, ao desenvolvimento das estradas de ferro, á construção e melhoramento das estradas de rodagem, á diffusão do ensino agricola; resulta ainda dos apparelhos de credito agricola organisados (sic) e funccionando de modo admiravel.
\end{abstract}

A fórmula do sucesso que Roberto Simonsen via na agropecuária angloamericana e que ele insistia que o ministro inplementasse em sua pasta estava na adoção da lógica industrial.

O Cultivador americano transportou para o campo os ensinamentos da moderna organização industrial, da organização scientífica; dirige sua fazenda como uma manufatura ou casa de commercio, multiplica a capacidade productiva de suas terras, substituindo o braço custoso e raro pela intelligencia, pelo talento inventivo, pela organização. (Simonsen, 1919, p. 23).

E qual seria, nessa dinamização da economia agropecuária, o peso ou a função do Estado, particularmente do Ministério da Agricultura? É nos EUA que Roberto Simonsen queria que Pádua Sales se orientasse e buscasse referências para suas políticas de governo. 
A acção do Estado nada tem ali de burocrática. Os campos de experiencia e demonstração espalhados por toda a Republica; as publicações gratuitas de propaganda e ensino; a larga distribuição de sementes; os agentes scientificos que por todo o globo procuram, sem cessar, novas plantas, novos grãos, que possam ser introduzidos com successo nos Estados Unidos; a diffusão do ensino agricola; os meios de consulta, demonstram a sábia orientação do Estado Americano nesse assumpto. (Simonsen, 1919, p. 23).

E sobre como lidar com as adversidades naturais, num país de dimensões continentais? Como colonizar e tornar produtivas a vastidão de terras longínquas brasileiras? Como lidar com a seca no sertão semiárido nordestino? Até nisso, Roberto Simonsen via exemplos nos EUA a serem seguidos pelo Brasil. Afinal, o "(...) cultivador americano, na ancia de extender os seus dominios, teve tambem de abordar terras rebeldes e insociaveis" (Simonsen, 1919, p. 24). E os exemplos anglo-americanos não estavam apenas na aplicação da ciência e da técnica. Os anglo-americanos eram também exemplares no estado de espírito, na persistência e na superação.

Nas terras da secca, "no pais da morte" como ficou denominado, apos os fracassos das primeiras colonizações em que os prejuizos totaes devidos a uma secca intensa, alcançaram cifras bem anglo-americanas, houve uma nova tentativa, uma nova onda de immigração. (Simonsen, 1919, p. 24).

Mas a razão do sucesso não era a disciplina cega ou a repetição do esforço. "Essa segunda investida, porém, não foi a simples repetição da primeira; novos methodos foram imaginados e apropriados pela experiencia, a esse clima semiarido" (Simonsen, 1919, p. 24). É preciso aprender com os erros e inovar e é nesse aspecto que deveria atuar o Estado, por meio do Ministério da Agricultura.

Rebuscando pelo Mundo, descobriram os Americanos uma vegetação de valor que resistia á secca. Inventaram um apparelho que paralysava a evaporação do sólo. A combinação desses instrumentos, desses methodos e desses grãos e plantas especiaes constitue o que os Americanos chamam a cultura a secco a qual permitiu vencer a aridez e cobrir de colheitas os milhões de hectares que, com os systemas communs de exploração, apenas serviriam para pastos de baixa qualidade. (Simonsen, 1919, p. 24).

Por fim, Roberto Simonsen toca no problema do crédito agrícola e da falta de braços para o trabalho agrícola, tão comum em economias industriais e em perspectiva de urbanização e de êxodo rural.

O fomento da nossa producção exige ainda o estudo do desenvolvimento do credito agricola; do problema da mão de obra, tão complexo no momento actual pela rarefação havida no mercado de braços; da orientação acertada na escolha dos productos e do instrumental agricola; do transporte, a preços modicos; depende, enfim, da organização da producção em bases scientificamente determinadas. (Destaques do autor). (Simonsen, 1919, p. 28)

O terceiro texto constitutivo do Trabalho moderno, distoando dos dois anteriores, não é um pronunciamento cerimonial, mas, sim, uma introdução a um relatório técnico apresentado em março de 1919 à diretoria da Companhia Construtora de Santos, da qual Roberto Simonsen era superintendente. Roberto Simonsen era metódico e adotava a prática de apresentar relatórios anuais às diretorias das empresas que comandava. Roberto Simonsen era pragmático, mas, 
também, reflexivo. Assim, em seus relatórios anuais, antes de focalizar os fatos administrativos, "(...) sempre fazia algumas divagações que, apesar de um tanto fora do campo concreto a que se cingem habitualmente exposições dessa natureza, sempre se relacionaram com successos ocorridos" (SIMONSEN 1919, p. 33) na esfera de suas atribuições. O foco da reflexão, na introdução desse relatório, era a reestruturação interna que Roberto Simonsen implementara na Companhia Construtora. Tais mudanças organizacionais, de acordo com Roberto Simonsen , visavam à implementação da administração científica, bem nos moldes das indústrias anglo-americanas.

E quais eram as divagações acerca das mudanças organizacionais implementadas na Companhia? Quais eram os objetivos de tais divagações? Roberto Simonsen demonstra em sua conduta ao lado dos seus colegas diretores uma ação educativa no sentido da formação de uma nova cultura empresarial: racional, separada da família e da tradição. Em função disso, as divagações que antecediam ao relato das mudanças e de seus resultados, visavam à exposição dos princípios ou dos valores subjacentes às práticas implementadas. $E$, já no ponto de partida, Simonsen (1919, p. 35) revela sua inspiração funcionalista e industrialista anglo-americana:

Encarei nossa empresa como genuinamene industrial. Os serviços contratados, como productos a fabricar. E em substituição ao antigo processo de administrar chamado pelos americanos "o militar" - em que, repetindo-se insensivelmente no crescimento de uma empresa (...) procuramos evoluir no sentido da administração "de funcção".

É na sequência da divagação que Roberto Simonsen dá novas pistas sobre o significado que atribui ao trabalho moderno ou o trabalho cientificamente orientado.

Nesse systema os factores: tempo, custo, execução e justa paga do trabalho, determinados por methodos scientificos, avultam como principaes elementos na procura de uma alta efficiencia, fim principal que deve almejar, avidamente, o trabalho moderno em todas as suas manifestações. (Simonsen, 1919, p. 35).

Mas o elemento principal da reflexão acerca dos princípios subjacentes ao trabalho moderno era referente à remuneração do trabalho e ao sistema de salários. No horizonte de Roberto Simonsen figurava uma sociedade capitalista e industrial. Entretanto, Simonsen demonstra, em suas palseus argumentos, um enorme abismo entre o capitalismo industrial europeu do século XIX e o capitalismo industrial angloamericano do século XX. As diferenças expressavam-se na cultura, na política e na economia. Mas a diferença mais significativa estava na relação entre capital e trabalho e na fundação de uma sociedade orientada pelo e para o mercado, capaz de sustentar-se em relações de classe que não fossem pautadas pelo conflito de interesses e pela violência da luta de classes. Roberto Simonsen, em seus textos constitutivos do Trabalho moderno, praticamente não faz referências à Europa e seu foco está todo nos EUA. Entretanto, ainda que não se ocupe de fazer considerações acerca da Europa, Roberto Simonsen, tal qual Alexis de Tocqueville (2000) no início do século XIX, percebia o envelhecimento e o anacronismo da plutocrática, conflitiva, revolucionária e violenta Europa, incapaz de acolher em sua cultura a emergência desse sujeito moderno que Tocqueville chamou de povo e que Marx chamou, um pouco mais tarde, de proletariado. A ausência de críticas 
explícitas à Europa pode ter vários motivos. Um desses motivos talvez fosse o viés diplomático, já presente no jovem Roberto Simonsen, que se ocuparia dessa função nos anos seguintes, no governo do presidente Epitácio Pessoa. Outro motivo, mais contundente, talvez fosse, mesmo, uma atitude de desprezo para com a velha Europa e sua capa de chumbo, marcada por um passado de servidão e de privilégios palacianos. Na condição de homem pragmático, preocupado em inserir o progresso num país rural, latifundiário, coronelista e ainda marcado pela mentalidade colonialista e escravocrata, Roberto Simonsen se inspirava era nas novas referências que se consolidavam nos EUA.

Entre essas referências estavam as novas relações de classe, de que Roberto Simonsen captava um novo critério de remuneração do trabalho e um novo sistema de salários. Essa era uma das novidades que a América apresentava ao mundo e que tanto encantava Roberto Simonsen. Para ele o sucesso angloamericano não estava apenas no domínio técnico e científico: "A Indústria moderna tem evoluido, como tudo" (Simonsen, 1919, p. 37). E para cada constatação ou para cada divagação o pragmático Simonsen (1919, p. 37) derivava uma orientação para a prática empresarial:

Os industriaes de hoje têm de abandonar os moldes antigos para considerar como uma força nova, existente realmente, o descontentamento do operario; e proporcionar, com desassombro, a justa remuneração ao trabalho, se não quiserem assistir ao entravamento da producção pela tentativa de decisão deste problema, erradamente, por vias polítifas , quando poderia ser resolvido, com acerto, por vias econômicas.

Ou seja, para Roberto Simonsen, os conflitos de interesse entre capital e trabalho eram decorrentes das práticas empresariais anacrônicas e de uma cultura empresarial que insistia em transferir para o Estado ou para a política uma questão que era da empresa e da economia: as práticas salariais ou a remuneração do trabalho. Em outras palavras, para conter a rebelião proletária, a solução não estava na repressão, mas, sim, na justa remuneração. Para Roberto Simonsen (1919, p. 38), a solução para a guerra de classes estavam na superação dos "(...) atrazados systemas de paga e a má orientação dos patrões que mais concorreram para que os trabalhadores se organizassem em feição de classe". Essa era uma herança da velha cultura empresarial europeia, da qual os industriais brasileiros deveriam desvencilhar-se: "As classes patronaes nos velhos paizes industriaes, salvo raras excepções, tratam sempre os operarios como se estes constituissem uma massa unica, não individualizando competências (...)" (Simonsen 1919, p. 38). A crítica a essa velha prática industrial era contundente. Nela os gestores empresariais davam menos atenção ao trabalho do que à matéria-prima, que sempre era buscada no mercado de forma criteriosa e individualizada. $O$ resultado dessa prática era inevitável. Ela induzia os trabalhadores, "(...) naturalmente, a se unirem em partido para obterem melhoria em remuneração e tratamento" (SIMONSEN 1919, 38), levando para a agenda política aquilo que de fato era da economia, para o Estado aquilo que era da empresa ou para a repressão aquilo que era da nogociação.

Para Simonsen (1919, p. 39), o “(...) mau systema de remuneração dos serviços é o maior, senão quasi o unico causador da greves". A solução, identificada, adotada e recomendada por Simonsen (1919, p. 39) vinha do angloamericano "Gantt, no seu magistral estudo 'Work, Wages and Profits' (...)". É nessa fonte que Simonsen (1919, p. 39) se inspirava na definição daquilo que constituía a “(...) justa paga do verdeiro rendimento do trabalho - estabelecida de modo a preminar com equidade o esforço pessoal $e$ as desigualdades fataes da 
productividade de um homem para outro". O resutado desse processo seria a individualização do "(...) operario, interessando-o diretamente na producção, tornando-o um factor crescente da riqueza e incorporndo-o na sociedade, por meios econômicos, já que della foi afatado por erros econômicos" (SIMONSEN, 1919, p. 39-40). No horizonte de expactativas de Simonsen figurava uma sociedade diferente da conflitiva Europa. Uma sociedade inspirada no modelo angloamericano e "(...) sua forma scientífica de adminstrar e retribuir o trabalho, em que se beneficiem lealmente as duas classes, (...) collocando ambas as partes em intima cooperação (...)" (SIMONSEN, 1919, p. 40).

Se a primeira divagação de Roberto Simonsen é no que toca à forma de remuneração do trabalho, a segunda é referente ao sistema de salários. Roberto Simonsen constata duas práticas dominantes nos países industriais da época: o sistema de remuneração por jornada e o sistema de remuneração por tarefa. Para ele ambos os sistemas eram falhos e a superação vinha da cultura industrial angloamericana:

\footnotetext{
Aos industriaes americanos cabe a iniciativa da criação e estabelecimento de systemas de salarios fundados em, pesquizas scientificas, em que se procura dar a cada homem 0 resutado do seu proprio esforço, em proporção à grandeza e ao tempo empregado em exercê-lo. (Simonsen, 1919, p. 42).
}

\section{Considerações finais}

A meta da abordagem aqui realizada foi trazer à tona a presença do angloamericanismo na preparação da aceleração industrial brasileira e suas implicações, tal qual ocorreu na primeira metade do século XX. De modo particular, a meta foi demonstrar articulações que envolvessem os antecedentes do boom de industrialização dos anos 1940 em diante e uma requisição que daí emergiu: formação dos novos homens da indústria. Ou seja, formação de nova cultura empresarial, inspirada na administração científica da produção e do trabalho e formação da nova força de trabalho, apta ao organograma, ao cronograma, à impessoalidade da gerência e às prescrições do posto de trabalho. De modo particular, a meta foi demonstrar a presença do anglo-americanismo em escritos de Roberto Simonsen, esse intelectual orgânico do industrialismo brasileiro, empenhado em difundir práticas de administração científica da produção e do trabalho.

O anglo-americanismo constitui uma acontecimento inédito, com desdobramentos diversos na economia, na política, na cultura ou na educação. Meados do século XX, constitui um momento relevante na afirmação do angloamericanismo e em sua repercussão no Brasil. Os anos 1940 foram emblemáticos da presença dos EUA na vida brasileira, tanto na aceleração da industrialização, quanto na instituição das redes de ensino industrial. No tocante à industrialização, a presença dos EUA deu-se por meio de dois movimentos. Por um lado, a inversão da balança comercial brasileira: os EUA tanto reduziram as exportações para o Brasil quanto aumentaram as importações de produtos brasileiros. Por outro lado, os EUA interferiram diretamente no incremento da indústria brasileira por meio da transferência de capitais, técnicas e técnicos. Mas o crescimento da indústria fez emergir a demanda pela força de trabalho industrial. O Brasil não dispunha de trabalhadores e de técnicos na proporção demandada e prospectada nem tinha instituições e experiência para formá-los com agilidade e em quantidade. Para isso 
é que foram instituídas as redes de ensino industrial, o que tornou necessário formar professores para o ensino industrial: conhecedores do ofício, da didática e da psicologia do ensino industrial. Foi aí que entrou em cena a Comissão Brasileiro Anglo-americana de Ensino Industrial (CBAI), que realizou intercâmbios entre professores dos dois países, traduziu livros e ministrou cursos com materiais e técnicas de origem norte-anglo-americana.

Mas, para que toda essa circulação de ideias, de práticas, de técnicos e de técnicas anglo-americanas se efetivasse intensamente no Brasil dos anos 1940 em diante, foi necessário um lento processo de fecundação do terreno. É nesse sentido que foi importante a intervenção de agentes como Monteiro Lobato, Anísio Teixeira, Lourenço Filho e Roberto Simonsen. Foram homens que descobriram a América, ou seja, homens que na primeira metade do século XX difundiram o sentido referencial dos EUA para o Brasil. Foram intelectuais americófilos que realizaram viagens aos EUA e que circularam sistematicamente ideias anglo-americanas no Brasil. Roberto Simonsen teve papel importante na difusão dos princípios e das práticas da administração científica da produção e do trabalho. Talvez uma diferença relevante entre Roberto Simonsen e seus contemporâneos americófilos seja a sua condição de homem da indústria, sua atuação política e a sua influência na cultura empresarial brasileira. Roberto Simonsen foi um inovador da gestão industrial, foi homem de referência para o industrialismo nascente. Sua condição de homem de referência vinha de sua prática e de seus pronunciamentos, de sua fala e de seus escritos. Roberto Simonsen praticava nas empresas que dirigia as ideias que difundia nos meios empresariais. Sua atuação ultrapassava o âmbito interno das empresas que dirigia e adentrava a cena política num Brasil fortemente latifundiário, coronelista e marcado pela herança escravocrata.

Roberto Simonsen foi figura importante na formação do pensamento industrial brasileiro na primeira metade do século XX. Roberto Simonsen tinha admiração particular pelas referências que vinham do norte. Suas elaborações presentes n'O trabalho moderno revelam que sua atitude era de preparar caminhos para aproximações cada vez maiores entre o Brasil e os EUA.

Roberto Simonsen era um homem preocupado com a superação do atraso econômico e cultural brasileiro e enxergava os EUA como uma referência. Além disso, Roberto Simonsen não via referências apenas nas técnicas de gestão da produção e do trabalho, mas, também, no modus vivendi da anglo-americanidade, no novo vigor do capitalismo industrial, incrementado com novas formas de hegemonia que contemplavam a elevação da produtividade a níveis inéditos, a massificação do consumo e novas práticas de regulação.

\section{Referências}

Durkheim, D. É. (1985). Da divisão do trabalho social. São Paulo: Martins Fontes.

Horkheimer, M. \& Adorno, T. (1985). Dialética do esclarecimento: fragmentos filosóficos. Rio de Janeiro: Jorge Zahar

Gramsci, A. (2001). Cadernos do cárcere. Rio de Janeiro: Civilização Brasileira. v. 4.

Hobbes, T. (1983). Leviatã ou matéria, forma e poder de um Estado eclesiástico e civil. São Paulo: Abril. (Coleção Os Pensadores). 
Lefebvre, H. (2001). A cidade do capital. Rio de Janeiro: DP\&A.

Lobato, J. B. M. (1950). América: os Estados Unidos de 1929. São Paulo: Brasiliense.

Moog, C. V. (2000). Bandeirantes e Pioneiros: paralelo entre duas culturas. Rio de Janeiro: Graphia.

Maquiavel, N. (MCMLXXVI). O príncipe. São Paulo: Cultrtix.

Marx, K. (1982). O capital; crítica da economia política. São Paulo: Difel. I.1, v.2

Pedrosa, J. G. \& Ramos, N. M. T. (2020). A educação profissional brasileira dos anos 1920 aos 1950 na escrita de Francisco Montojos (1900-1981). História Revista, 25(2), 246-266.

Pinto. Á. V. (2005). O conceito de tecnologia. Rio de Janeiro: Contraponto. v.1

Simonsen, R. C. (1919). O trabalho moderno. São Paulo: Secção de obras do Estado.

Sirinelli, J. F. (1996). Os intelectuais, In Rémond, René (Org.) (1996). Por uma história política, Rio de Janeiro: UFRJ.

Touraine, A. (1997). Crítica da modernidade (4a edição). Petrópolis: Vozes.

Tocqueville, A. (2000). A democracia na América: sentimentos e opiniões. São Paulo: Martins Fontes.

Vieira, C. E. (2012) Intelligentsia e intelectuais: sentidos, conceitos e possibilidadews para a história intelectual. Revista Brasileira de História da Educação, 8 (1- [16]), 63-85.

Warde, M. J. (2000). Anglo-americanismo e educação: um ensaio no espelho. São Paulo em Perspectiva, 14, (2),16-40.

Weber, M. (1993). Ciência e política: duas vocações (5a edição). São Paulo: Cultrix.

\section{Notas:}

\footnotetext{
${ }^{1}$ A expressão "cabeça de obra" como referência ao técnico foi utilizada por Álvaro Vieira Pinto em seu clássico livro "O conceito de tecnologia" (Pinto, 2005).
}

${ }^{2}$ Francisco Belmonte Montojos (1900- ?), formou-se em Engenharia Civil pela Escola de Engenharia de Porto Alegre em 1925. Além de ser um lugar de circulação do pensamento industrialista, a Escola de Engenharia, tal qual a Politécnica de São Paulo, tinha como anexo um espaço de ensino industrial, destinado à formação de trabalhadores: o Instituto Parobé, que mais tarde, juntamente com a Escola Mecânica da Politécnica de São Paulo, foram referências para o CFESP (Centro Ferroviário de Ensino e Seleção Profissional) e este para o SENAI. Montojos ingressou no Governo Federal em 1927 no Ensino Profissional e Técnico e em 1934 passou atuar diretamente no ensino industrial, como superintendente. Foi Diretor do Ensino Industrial do Ministério da Educação e Saúde Pública (MESP) por um longo período, de 1937 a 1949 e de 1955 a 1961, tendo sido também superintendente da Comissão Brasileiro-Americana de Educação Industrial (CBAI) por dois mandatos entre 1946 e 1949 e 1955 a 1961. (Pedrosa, 2020)

${ }^{3}$ Nascida em Minas Gerais (1839), foi professora, tradutora e escritora.

${ }^{4}$ Nascido no Maranhão, atuou como advogado, jornalista e professor. Foi deputado e presidente provincial.

5 Moog viajou com projeto financiado pela Fundação Ford e com objetivo de escrever um livro comparando os dois países, seus povos e suas instituições. A experiência de Moog foi após a

History of Education in Latin America - HistELA, v. 4, e26851, 2021, p. 19 de 20 
Segunda Guerra. As elaborações de Moog permitem pensar nas condições que possibilitaram a gênese do acontecimento anglo-americano. O resultado da pesquisa de Moog veio uma década mais tarde, com a publicação de Bandeirantes e Pioneiros: paralelo entre duas culturas. (Moog, 2000).

${ }^{6}$ Esses adjetivos são apresentados por Vieira (2008, p. 68) como referência a Dmitre, personagem da novela Rudin (1856), que encarna "o protótipo da inteligência".

${ }^{7}$ Esta e as demais citações textuais de Simonsen são transcritas em sua forma original conforme a grafia de 1919. 